\title{
D-Periodic Collagen-Mimetic Microfibers
}

\author{
Shyam Rele, ${ }^{1}$ Yuhua Song, ${ }^{2}$ Robert P. Apkarian, ${ }^{3}$ Zheng Qu, ${ }^{1}$ \\ Vincent P. Conticello, ${ }^{3^{*}}$ and Elliot L. Chaikof ${ }^{1,4^{*}}$
}

\section{${ }^{1}$ Departments of Surgery and Biomedical Engineering, Emory University School of Medicine, ${ }^{2}$ Department of Biomedical Engineering, University of Alabama at Birmingham, Birmingham, AL, 35294 \\ ${ }^{3}$ Department of Chemistry, Emory University, Atlanta, GA 30322, and ${ }^{4}$ School of Chemical and Biomolecular Engineering, Georgia Institute of Technology, Atlanta, GA 30332}

Supporting Information for a Revised Article submitted to the Journal of the American Chemical Society

MS\# JA0758990-31-256

*Address correspondence to:

Elliot L. Chaikof, M.D., Ph.D. or Vincent P. Conticello, Ph.D. Emory University

101 Woodruff Circle, Rm 5105

Atlanta, GA 30322

Tel: (404) 727-8413

Fax: (404)-727-3660

E-mail: echaiko@emory.edu or vcontic@emory.edu 


\section{METHODS}

\section{Materials}

Fmoc-protected amino acids, Fmoc-Gly, Fmoc-Arg(PMC)-OH (PMC: 2,2,5,7,8pentamethylchroman-6-sulfonyl group), Fmoc-Glu(Ot-Bu)-OH (t-Bu: tert-butyl protecting group), Fmoc-Pro-OH and Fmoc-Hyp(t-Bu)-OH and Wang resin (substitution level $0.66 \mu \mathrm{mol} / \mathrm{g}$ ) were purchased from Novabiochem. Activating agent DCC/HOBt, dichloromethane (anhydrous $\mathrm{CH}_{2} \mathrm{Cl}_{2}$ ), N-methylpyrrolidone (NMP), and dimethylformamide (DMF) were purchased from Applied Biosystems (Foster City, CA), while 20\% (v/v) piperidine in DMF was obtained from Advanced Chemtech (Louisville, KY). N-ethyldiisopropylamine (DIEA), 1,2-dithioethane, trifluoroacetic acid (TFA), and thioanisole were obtained from Fluka Chemicals (Seelze, Germany), acetic anhydride from Fisher Scientific (Waltham, MA), and diethyl ether and phenol purchased from Aldrich (St. Louis, MO). N-[tris(hydroxymethyl)methyl]-2-aminoethanesulfonic acid (TES) and all other reagents for buffer solutions were purchased from Aldrich.

\section{Peptide Synthesis}

The collagen-mimetic peptide, $\mathrm{NH}_{2}$-(Pro-Arg-Gly) ${ }_{4}$-(Pro-Hyp-Gly) $)_{4}-(\text { Glu-Hyp-Gly })_{4}$ $\mathrm{COOH}, \mathrm{CPII}$, was synthesized by a solid phase synthetic strategy using Applied Biosystems Model 433A automated peptide synthesizer using standard Fmoc chemistry. Stepwise chain elongation of the peptide was monitored throughout by high-pressure liquid chromatography (HPLC) and matrix-assisted laser desorption/ionization time-of-flight (MALDI-TOF) mass spectrometry. For Fmoc solid phase peptide synthesis, Wang resins were used and stepwise elongation of the amino acids was accomplished by activating Fmoc amino acids using DCC/HOBt coupling reagent. The couplings were performed in NMP as a solvent. The complete cleavage of the Fmoc group during individual coupling steps was carried out by base-induced deprotection using $20 \%(\mathrm{v} / \mathrm{v})$ piperidine in DMF. The synthesis was run in $0.25 \mathrm{mmol}$ scale with iterative coupling conditions involving 10-fold excess of Fmoc-protected reacting amino acids. 
Conditional double coupling of unreacted amino groups with acetic anhydride $\left(\mathrm{Ac}_{2} \mathrm{O}\right)$ was used in coupling steps involving Hyp, Pro and Arg, in order to obtain high yield of the desired product and minimize the formation of side products. On completion of the final amino acid coupling (proline) in the sequence, removal of side-chain protecting groups was achieved using acidmediated cleavage with trifluoroacetic acid (TFA). The N-terminus of the peptide was not capped with acetic anhydride prior to its cleavage from the resin.

Peptides were cleaved off the resin at $25^{\circ} \mathrm{C}$ using $10 \mathrm{~mL}$ 'cocktail' of thioanisole $(1.25$ $\mathrm{mL}) /$ ethanedithiol $(0.625 \mathrm{~mL}) /$ phenol $(1.875 \mathrm{~g}) /$ water $(1.25 \mathrm{~mL})$ diluted in $25 \mathrm{~mL}$ of TFA $(100 \%)$ over a period of $150 \mathrm{~min}$. This procedure afforded a collagen-like peptide with a free $\mathrm{COOH}$ and amino group at the $\mathrm{N}$ and $\mathrm{C}$ terminus, respectively. The crude peptide was precipitated overnight with cold diethyl ether, filtered through a sintered funnel, and extracted over 20 min with $30 \%$ aqueous acetic acid and washed five times with distilled water (10 mL). Lyophilization yielded $570 \mathrm{mg}$ of a white cotton-like material.

\section{HPLC Purification}

The crude peptide was dissolved in formic acid/TFA/trifluroethanol/water $(1: 1: 4, \mathrm{v} / \mathrm{v})$ and purified by preparative reversed phase (RP) HPLC on a Zorbax SB C18 silica column (22 x 250 $\mathrm{mm}, 5 \mathrm{~mm}$ particle size, $300 \AA$ pore size, Agilent) equilibrated at room temperature in $0.1 \%$ aqueous TFA. The peptide was eluted using a linear gradient of acetonitrile $(\mathrm{AcN})$ in $0.08 \%$ aqueous TFA at $25^{\circ} \mathrm{C}$ at a flow rate of $5 \mathrm{~mL} / \mathrm{min}$. Specifically, the gradient was created using two solvents. Solvent $A$ consisting of $0.1 \%$ TFA in $\mathrm{H}_{2} \mathrm{O}$ and solvent $\mathrm{B}$, which was acetonitrile $(\mathrm{AcN})$ in $0.08 \%$ aqueous TFA ( $\mathrm{v} / \mathrm{v}, 0.08 \%$ TFA). The gradient conditions were $3 \%$ solvent $\mathrm{B}$ for $10 \mathrm{~min}, 3-15 \%$ solvent $B$ for $35 \mathrm{~min}, 15-65 \%$ solvent $B$ for $110 \mathrm{~min}, 65-100 \%$ solvent B for 120 min, $100 \%$ solvent B for $130 \mathrm{~min}$. The column effluent was monitored at $235 \mathrm{~nm}$ and the eluate was manually collected and stored at room temperature prior to further analysis. 
The purity and the integrity of the HPLC fractions were screened by MALDI-TOF (Voyager-DE STR instrument (PerSeptive Biosystems, Framingham, MA) and those fractions containing the desired product were pooled. Rechromatography of some of the enriched fractions, which were lyophilized prior to their HPLC purification, was carried out using the same above mentioned conditions to obtain the final material in high purity. Subsequent lyophilization of the repurified fractions furnished CPII (320 mg) in 98\% purity as demonstrated by MALDITOF MS and analytical HPLC.

Analytical HPLC of peptides was carried out using microbore RP-HPLC consisting of a Model 140A solvent delivery system and a Model 1000S diode array UV detector (Applied Biosystems). The separation was achieved using a Zorbax SB-C18 column (3m C-18 silica column $4.6 \times 50 \mathrm{~mm}, 120 \mathrm{~A} \mathrm{mBore}$ ) equilibrated at $25^{\circ} \mathrm{C}$ in $0.1 \%$ TFA and developed at a flow rate of $90 \mathrm{~mL} / \mathrm{min}$ using a linear gradient of acetonitrile. The column eluate was monitored at $214 \mathrm{~nm}$ and eluted at $30^{\circ} \mathrm{C}$ using linear gradient of acetonitrile in $0.1 \%$ TFA (Figure $1 \mathrm{~S}$ ).

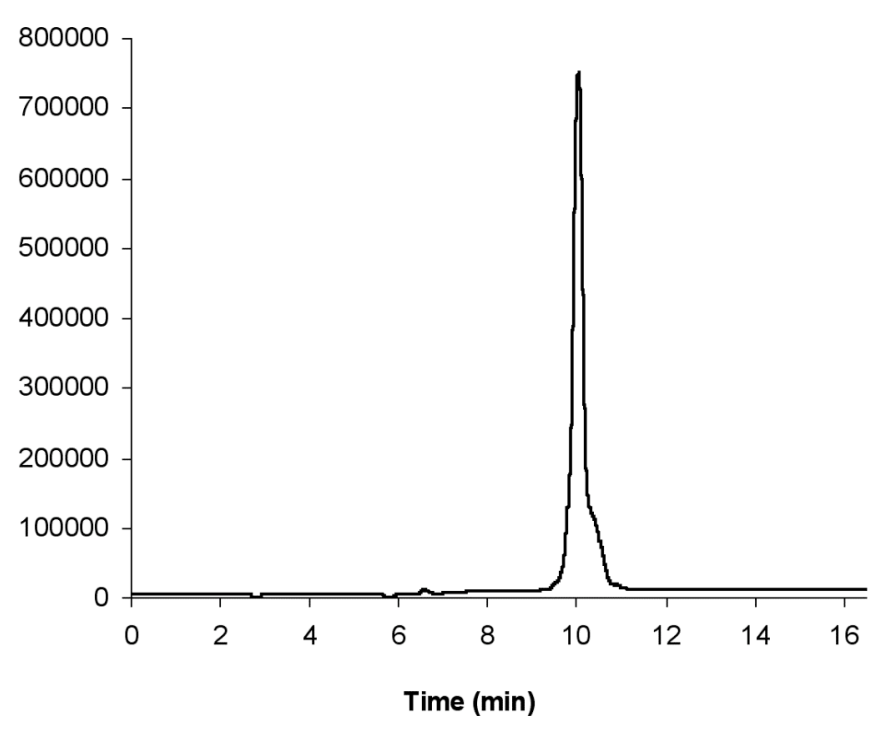

Figure 1S. Reverse phase analytical HPLC profile of purified CPII.

Conditions: Zorbax SB-C18 column ( $3 \mu \mathrm{C}-18$ silica column 4.6 X $50 \mathrm{~mm}, 120 \mathrm{~A} \mathrm{mBore}), 30{ }^{\circ} \mathrm{C}$, $90 \mathrm{ml} / \mathrm{min}$, linear gradient of acetonitrile in $0.1 \%$ TFA. Rt $=10.05 \mathrm{~min}$. Solvent A: $0.1 \%$ TFA in $\mathrm{H}_{2} \mathrm{O}$, Solvent B: $80 \% \operatorname{AcN}(v / v, 0.08 \%$ TFA). 


\section{Mass Spectroscopy Analysis}

MALDI-TOF MS analysis was performed using a Model Reflex III mass spectrometer (Bruker, Billarica, MA) equipped with a 337-nm nitrogen laser or MALDI-TOF Voyager program module and/or Voyager-DE STR BioSpectrometry Workstation MALDI-TOF mass spectrometer (Perseptive Biosystems, Inc., Framingham, MA, USA). $\alpha$-Cyano-4-hydroxycinnamic acid (MALDI-Quality, Hewlett-Packard, Palo Alto, CA) was used as the matrix. The HPLC fractions $(0.3 \mu \mathrm{L})$ were spotted on a target site of a sample grid, followed by addition of $0.3 \mu \mathrm{L}$ of matrix (saturated $\alpha$-cyano-4-hydroxycinnamic acid) dissolved in ethanol/water $(1: 1, \mathrm{v} / \mathrm{v})$. The sample matrix was allowed to dry at room temperature for $5 \mathrm{~min}$, and each sample was desorbed with 100 laser shots, each giving a spectrum. Measurements were performed at an acceleration voltage of $20 \mathrm{kV}$ and spectra averaged to give the final spectrum. The instrument was operated in the reflector mode and was calibrated using the external standard peptides. MALDI-TOF mass spectrum (m/z): calcd, 3525.71; obsd, 3524.91 (monoisotopic mass) (Figure 2S).

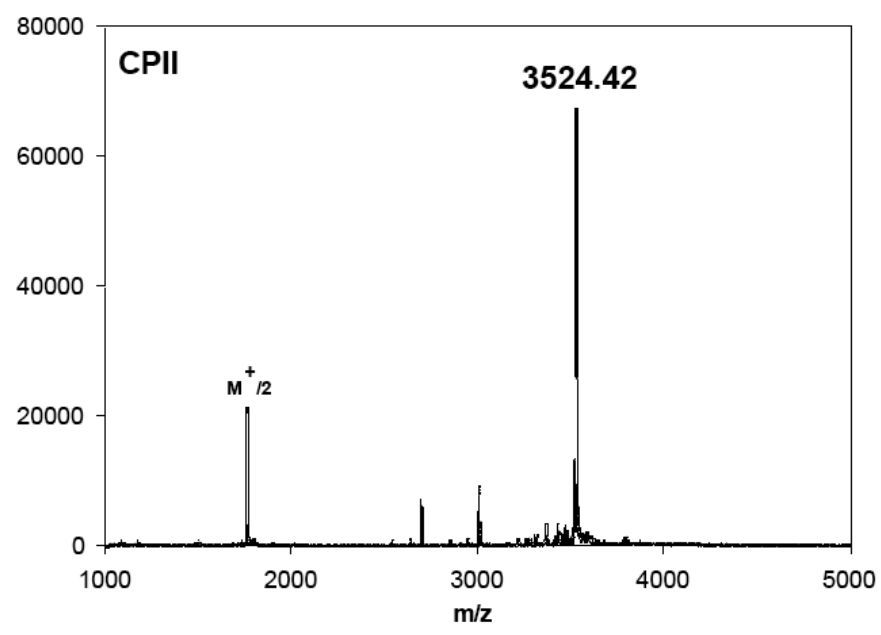

Figure 2S. MALDI-TOF mass spectroscopy purified CPII. Matrix: a-cyano-4-hydroxycinnamic acid. calcd, 3525.71; obsd, 3524.91 (monoisotopic mass). 


\section{Circular Dichroism Spectroscopy}

CD spectra were obtained on a JASCO J-810 CD spectropolarimeter (Jasco Inc., Easton, MD) equipped with a PFD-425S Peltier temperature control unit. Peptide solutions (0.5 $\mathrm{mg} / \mathrm{mL}, 142 \mu \mathrm{M}$ ) were prepared in various buffer solutions and allowed to equilibrate at $4{ }^{\circ} \mathrm{C}$ for $24 \mathrm{~h}$ and spectra acquired from $5{ }^{\circ} \mathrm{C}$ to $25^{\circ} \mathrm{C}$, averaging 10 scans between $190-260 \mathrm{~nm}$ at 2 $\mathrm{nm}$ intervals and a $2 \mathrm{~nm}$ bandwidth. The scan rate was $20 \mathrm{~nm} \mathrm{min-1}$ with a 4 second response time. Spectra were baseline corrected before converting to mean residue ellipticities $[\theta]$. CD melting curves were generated by monitoring the absorbance at $222 \mathrm{~nm}$, while the temperature was increased $2{ }^{\circ} \mathrm{C} / \mathrm{min}$ from 20 to $100^{\circ} \mathrm{C}$ with an equilibration time of $1 \mathrm{~min}$ at each temperature. The $T m$ values were determined from the first derivative $d[\theta] / d T$ of the $C D$ melting curve (Table 1S).

Table 1S. Solvent dependant melting temperatures (Tm) for triple helical collagen-mimetic peptide CPII

\begin{tabular}{lc}
\multicolumn{1}{c}{ Buffer System } & Tm $\left({ }^{\circ} \mathbf{C}\right)$ \\
Buffer 1 $\left(\mathrm{H}_{2} \mathrm{O}\right)$ & 44.4 \\
Buffer 2 (10 mM HCl, pH 3.5) & 38.9 \\
Buffer 3 (10 mM MOPS, pH 6.85) & 38.6 \\
Buffer 4 (PBS, pH 7.25) & 48.8 \\
Buffer 7 (10 mM CHES, pH 9.0) & 48.4 \\
Buffer 8* (30 mM TES, pH 7.4) & 37.4
\end{tabular}

${ }^{*}$ Buffer 8: $30 \mathrm{mM} \mathrm{Na}_{2} \mathrm{HPO}_{4}, 30 \mathrm{mM}$ TES, $135 \mathrm{mM} \mathrm{NaCl}$ (ionic strength 0.225), pH 7.4

\section{Turbidity Measurements}

The turbidity profiles for native collagen Type I and collagen-mimetic peptide CPII were acquired by monitoring the optical density at $313 \mathrm{~nm}$ as a function of time using a Cary 50 UVvis spectrophotometer with attached Peltier temperature controller. All turbidity measurements were performed in a sealed cell to minimize evaporative losses and repeated a minimum of three times. For comparative analysis, turbidimetric analyses were determined for collagen 
Type I at concentrations and temperatures between $0.2-1.0 \mathrm{mg} / \mathrm{mL}$ and $26-37^{\circ} \mathrm{C}$, respectively. The isolation and purification of monomeric collagen type I from rat tail tendon followed protocols detailed elsewhere. ${ }^{1,2}$ Fibril formation was initiated using a "cold-start procedure" by mixing $0.5 \mathrm{~mL}$ of collagen dissolved in $10 \mathrm{mM} \mathrm{HCl}$ with $0.5 \mathrm{~mL}$ of buffer solution to yield a final buffer composition of $30 \mathrm{mM} \mathrm{TES}, 30 \mathrm{mM} \mathrm{Na}{ }_{2} \mathrm{HPO}_{4} \cdot 7 \mathrm{H}_{2} \mathrm{O}$, and $135 \mathrm{mM} \mathrm{NaCl}$ (ionic strength 0.225 ), $\mathrm{pH} 7.4$. Both collagen and buffer solutions were maintained at $4{ }^{\circ} \mathrm{C}$ prior to mixing and, thereafter, placed in the sample holder maintained at the experimental temperature (Figure 3S).

Collagen-mimetic peptide fibril forming solutions were prepared by adding $100 \mu \mathrm{L}$ of buffer to $600 \mu \mathrm{L}$ of peptide solution in $10 \mathrm{mM} \mathrm{HCl}$. Both solutions were maintained at $4{ }^{\circ} \mathrm{C}$ prior to mixing. The final peptide concentration ranged between $0.5-1.4 \mathrm{mg} / \mathrm{mL}$ in a final buffer composition of $30 \mathrm{mM}$ TES, $30 \mathrm{mM} \mathrm{Na} 2 \mathrm{HPO}_{4} \cdot 7 \mathrm{H}_{2} \mathrm{O}, 135 \mathrm{mM} \mathrm{NaCl}, \mathrm{pH}$ 7.4. The peptide solution was heated to $75^{\circ} \mathrm{C}$ for $40 \mathrm{~min}$ and then cooled to room temperature, after which the cuvette was placed in the UV-vis sample holder maintained at the target temperature for turbidity studies.

The turbidity curves were analyzed as described by Silver and Birk. ${ }^{3}$ Specifically, turbidity $\left(A_{313} \times 2.303\right)$ was plotted as a function of time in minutes to define the lag (tlag) and plateau times ( $\mathrm{tp})$ of the assembly process. Data obtained from turbidity-time assays at different peptide or collagen concentrations were used to calculate the apparent rate constants $(k)$ for the lag and growth phases of self-assembly by regression of plots of $c / t$ lag and $c /\left(t_{p}-t\right.$ lag $)$ versus concentration, respectively. The activation energy $\left(E_{a}\right)$ for each phase was determined using the Arrhenius equation, $k=A e^{-E a / R T}$, where $E_{a}$ can be from a plot of In $k$ versus $1 / T$. 

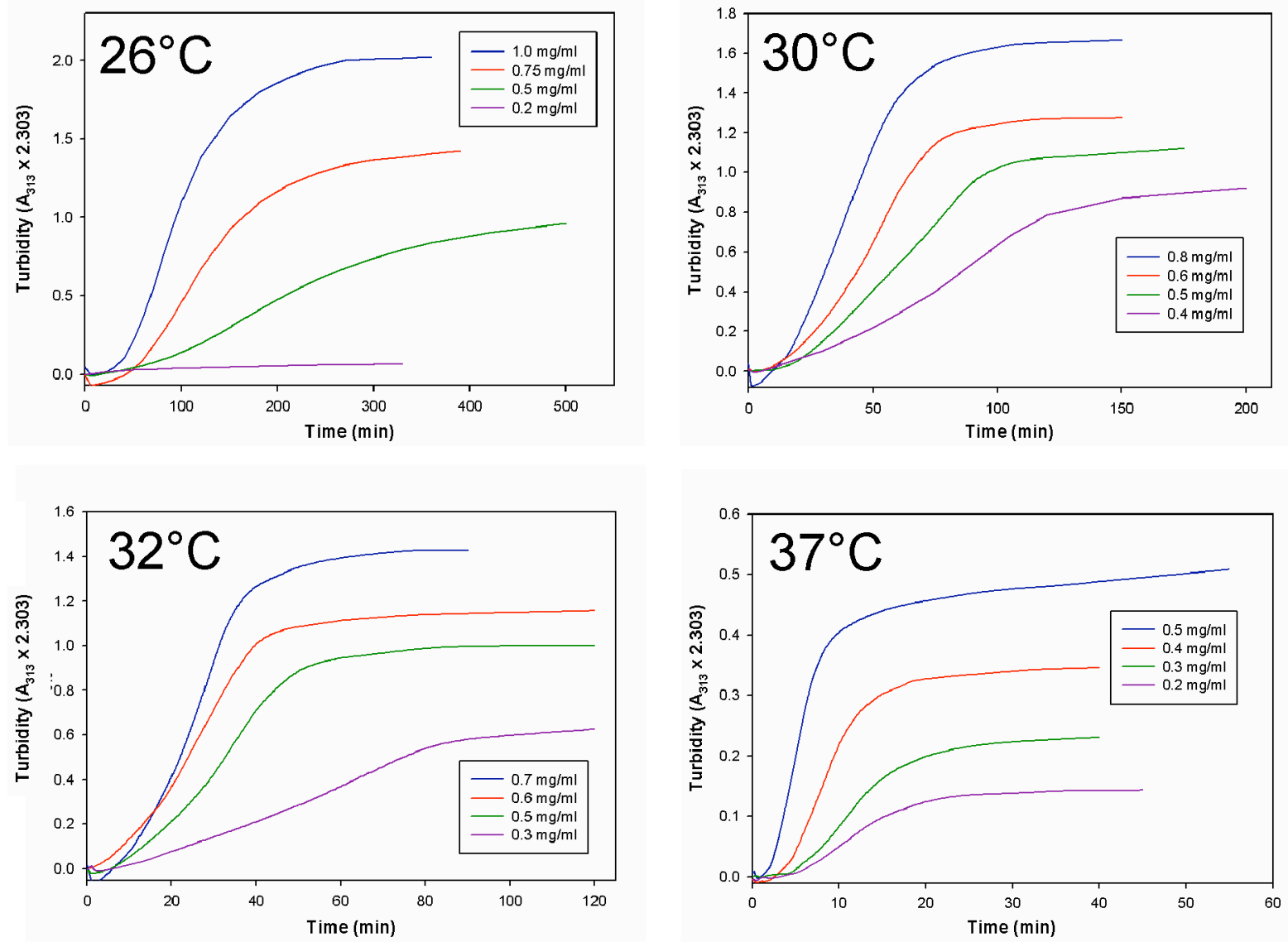

Figure 3S. Turbidity profiles for collagen Type I. Turbidimetric analyses were determined at concentrations between $0.2-1.0 \mathrm{mg} / \mathrm{mL}$ and temperatures between $26{ }^{\circ} \mathrm{C}$ and $37^{\circ} \mathrm{C}$.

Absorbance was acquired at $313 \mathrm{~nm}$ as a function of time and turbidity presented as $A_{313} \mathrm{X}$ 2.303. Characteristic sigmoidal plots with a lag region, a growth region, and a plateau were observed for Type I collagen with an enhancement in the rate and magnitude of self-assembly noted with increasing collagen concentration. The calculated Ea was $206 \mathrm{~kJ} \mathrm{~mol}^{-1}$ for the lag phase and $196 \mathrm{~kJ} \mathrm{~mol}^{-1}$ for the growth phase, which is similar to that reported by Silver et al. ${ }^{3}$

\section{Electron Microscopy}

A fibril forming solution was prepared, as described above, with a final concentration of $0.71 \mathrm{mg} / \mathrm{mL}$ of CPII in $30 \mathrm{mM}$ TES, $30 \mathrm{mM} \mathrm{Na}_{2} \mathrm{HPO}_{4} \cdot 7 \mathrm{H}_{2} \mathrm{O}$, and $135 \mathrm{mM} \mathrm{NaCl}$ at $\mathrm{pH}$ 7.4. The peptide solution was heated to $75^{\circ} \mathrm{C}$ for $40 \mathrm{~min}$ and then gradually cooled to room temperature, after which the sample was stored at $23^{\circ} \mathrm{C}$. After pre-defined incubation periods, $5 \mu \mathrm{L}$ of 
peptide solution was placed on 200 mesh Formvar-carbon film-coated copper grids, excess solution was removed with filter paper, and the sample stained with $0.5 \%$ uranyl acetate for 10 sec and then washed twice in water for $10 \mathrm{sec}$. The preparation was examined in a JEOL 1210 transmission electron microscope at $90 \mathrm{kV}$ accelerating voltage.

\section{Molecular Dynamics Simulations}

A total of five molecular dynamics (MD) simulations were performed with GROMACS version 3.3.1 in order to examine potential structural features that contribute to the assembly of CPII THPs, as well as to the formation of axially oriented staggered protomer-protomer assemblies (Table 2S). ${ }^{4}$ In brief, simulations were performed on a local Infiniband 2 dual core Xeon 5140 cluster with 64 processors using (i) steepest descent minimization; (ii) 20 ps of constant number-pressure-temperature (NpT) simulations at $-223^{\circ} \mathrm{C}$ and 1 atm to equilibrate water with mobile water molecules, but with peptides restrained; (iii) 10 ps of constant numbervolume-temperature (NVT) simulations at $-223,-173,-123,-73,-23$, and $23^{\circ} \mathrm{C}$ with SHAKE constraints and 2 fs time steps; and (iv) 5 to 10 ns of NpT simulation at $23^{\circ} \mathrm{C}$ and 1 atm to equilibrate the system. The Parrinello-Rahman pressure coupling algorithm ${ }^{5}$ was used to isotropically scale pressure with a time constant of $2 \mathrm{ps}$, while temperature was controlled using the Nosé-Hoover temperature coupling algorithm ${ }^{6}$ with a time constant of $0.5 \mathrm{ps.} \mathrm{SHAKE}$ constraints were used on all H-heavy atom bonds to permit a dynamic time step of $2 \mathrm{fs}$. Electrostatic interactions were calculated by the Particle Mesh Ewald (PME) method. ${ }^{7}$ In all cases, a periodic box was utilized with more than $1 \mathrm{~nm}$ of solvent between the peptide surface and box boundaries to reduce potential artifacts arising from periodicity. The box was filled with simple point charge (SPC) water molecules. ${ }^{8}$ For the data analysis, electrostatic potentials were calculated using APBS software ${ }^{9}$. The extent of hydrogen bond formation was calculated with tools in GROMACS 3.3.1. ${ }^{4}$ 
Table 2S: MD Simulations for CPII Peptide and Protomer Self-Assembly

\begin{tabular}{lll}
\hline System & Components & Component orientation \\
\hline 1: 3Peptide-Parallel & 3 peptides & Three parallel oriented peptides \\
2: 3 Peptide-Antiparallel & 3 peptides & Three anti-parallel oriented peptides \\
3: 3 Trihelix-Parallel & 3 triple helical protomers & $\begin{array}{l}\text { Assembly of three THPs, each formed from } \\
\text { parallel oriented peptides }\end{array}$ \\
4: 3 Trihelix-Antiparallel & 3 triple helical protomers & $\begin{array}{l}\text { Assembly of three THPs, each formed from anti- } \\
\text { parallel oriented peptides }\end{array}$ \\
5: 3 Complex-Parallel & 3 complexes & $\begin{array}{l}\text { Assembly of three complexes, each formed } \\
\text { from four THPs produced from parallel oriented } \\
\text { peptides }\end{array}$ \\
\hline
\end{tabular}

The initial structure for the CPII peptide was obtained by mutating the known X-ray crystal structure of [(Pro-Pro-Gly) $\left.{ }_{10}\right]_{3}$ (Protein ID: $\left.1 \mathrm{~K} 6 \mathrm{~F}\right)^{10}$ using the mutagenesis tools in Pymol ${ }^{11}$ followed by energy minimization. Molecular dynamics simulations were initially performed to examine the formation of a triple helix from CPII peptides either in parallel or anti-parallel orientation at a separation distance of $2 \mathrm{~nm}$ (Figure 4S: Case 1, 2). Water between the three peptides was manually removed to reduce computational time for the peptides to repel water from the assembly. ${ }^{12}$ Although the removal of water might influence the ability of the three CPII peptides to search for other conformations, the focus of this simulation was to investigate the structural features leading to THP assembly. CPII protomer-protomer interactions were subsequently investigated by simulating THPs produced from peptides assembled in either parallel or anti-parallel orientation, solvated in water, and separated by $2 \mathrm{~nm}$ (Figure $4 \mathrm{~S}$ : Case 3, 4). A second form of protomer-protomer interaction was also examined by simulating three linear complexes, each produced from four THPs that were initially assembled from three CPII peptides in parallel orientation. The three linear complexes were then solvated in water, separated by $2 \mathrm{~nm}$, and positioned in a parallel array (Figure 4S: Case 5). 


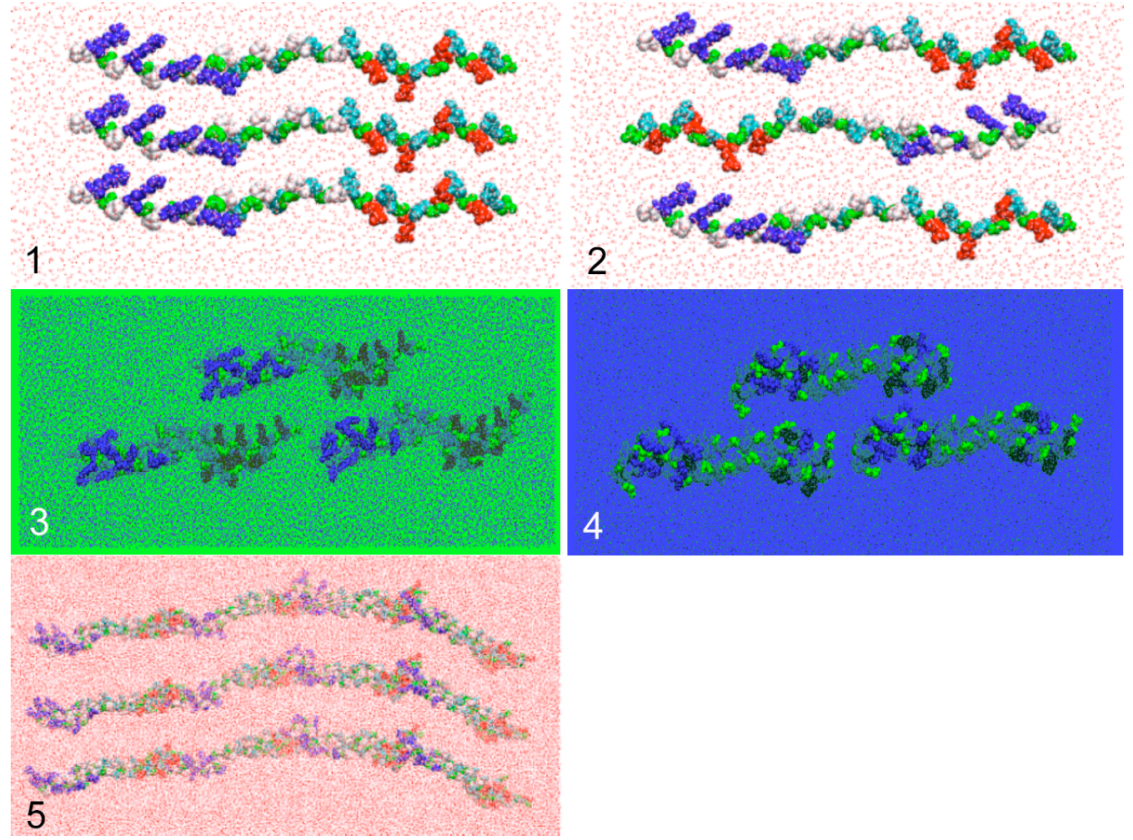

Figure 4S. Case 1: Three CPII peptides oriented in parallel and solvated in water. Case 2: Three CPII peptides oriented in anti-parallel and solvated in water. Case 3: Three triple helical protomers from parallel oriented CPII peptides solvated in water. Case 4: Three triple helical protomers from anti-parallel oriented CPII peptides solvated in water. Case 5: Three complexes each formed from four triple helical protomers initially produced from parallel oriented CPII peptides solvated in the water. Peptides are represented as residue type in VDW style, for residue type, blue: Arg; red: Glu; green: Gly; cyan: Hyp; white: Pro; red dot: water.
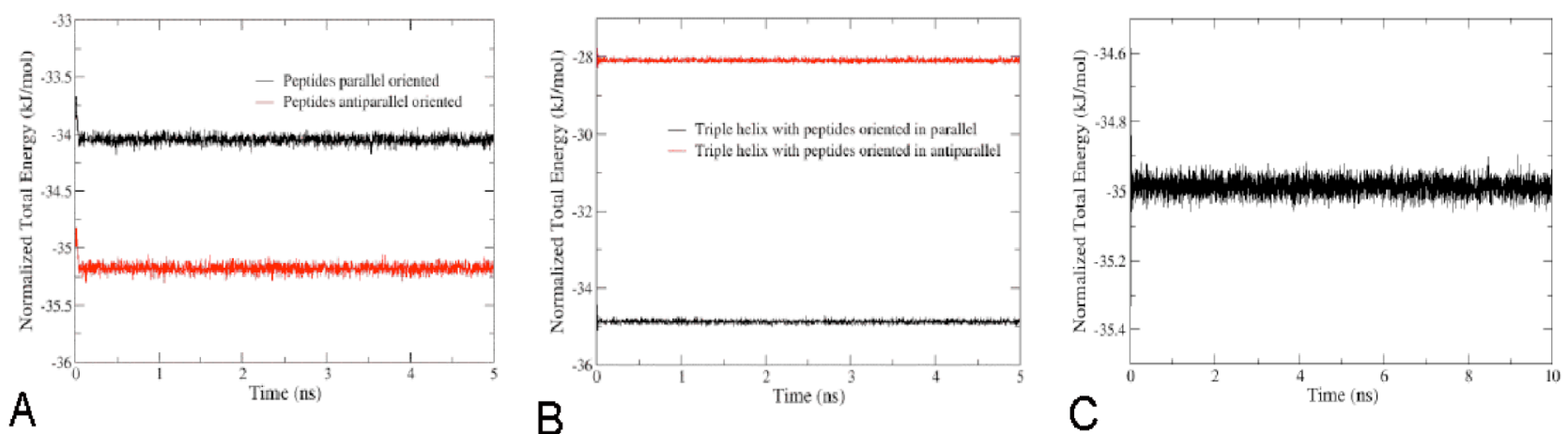

Figure 5S. System total energy normalized by the number of water molecules. (A) Assembly of three peptides to form triple helical promoter (Cases 1 and 2). (B) Assembly of triple helical promoters (Cases 3 and 4). (C) Assembly of complexes formed from triple helical protomers (Case 5). 


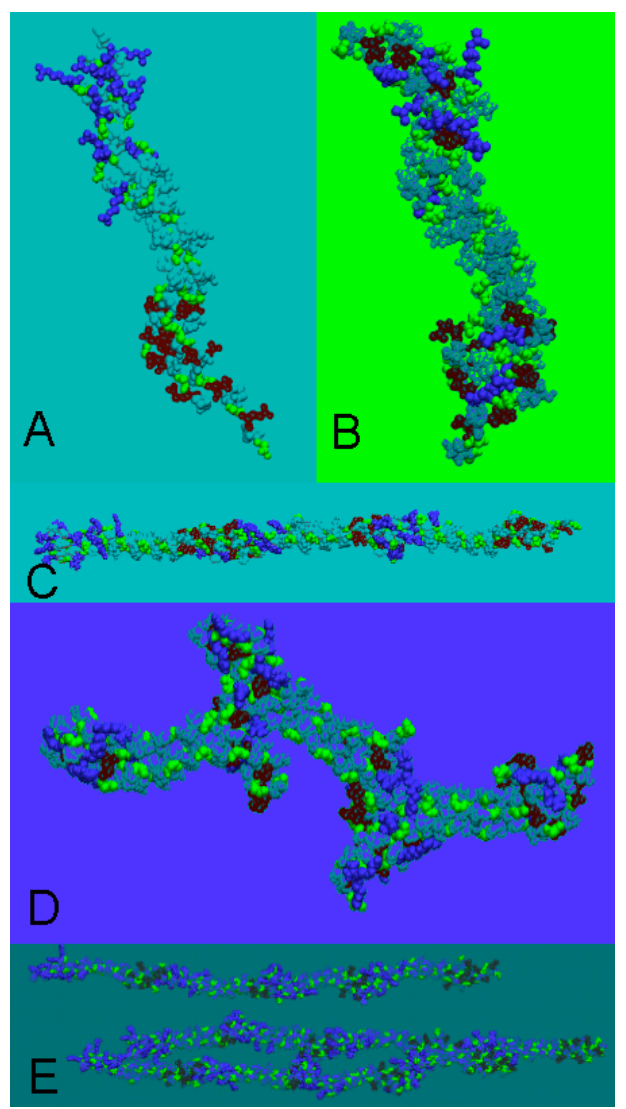

Figure 6S. Assembly results for different simulation cases. (A) Three peptides oriented in parallel (Case

1). (B) Three peptides oriented in anti-parallel (Case

2). (C) Three triple helical protomers from parallel oriented CPII peptides (Case 3). (D) Three triple helical protomers from anti-parallel oriented CPII peptides (Case 4). (E) Three complexes each formed from four triple helical protomers produced from parallel oriented CPII peptides (Case 5). The peptide was represented as residue type with VWD style separately, for residue type, blue: Arg; red: Glu; green: Gly; cyan: Hyp; white: Pro. The images were made with VMD software support. 


\section{REFERENCES}

1. Silver, F. H.; Trelstad, R. L. J Biol Chem 1980, 255, 9427.

2. Pins, G. D.; Christiansen, D. L.; Patel, R.; Silver, F. H. Biophys J 1997, 73, 2164.

3. Silver, F. H.; Birk, D. E. Coll Relat Res 1983, 3, 393.

4. Lindahl, E.; Hess, B.; van der Spoel, D. Journal of Molecular Modeling 2001, 7, 306.

5. Parrinello, M.; Rahman, A. J Appl Phys 1981, 52, 7182.

6. Hoover, W. G. Physical Review. A 1985, 31, 1695.

7. Darden, T.; York, D.; Pedersen, L. G. J Chem Phys 1993, 98, 10089.

8. Berendsen, H. J. C.; Grigera, J. R.; Straatsma, T. P. J Phys Chem 1987, 91, 6269.

9. Baker, N. A.; Sept, D.; Joseph, S.; Holst, M. J.; McCammon, J. A. Proc Natl Acad Sci USA 2001, 98, 10037.

10. Berisio, R.; Vitagliano, L.; Mazzarella, L.; Zagari, A. Protein Sci 2002, 11, 262.

11. DeLano, W. L. 2002, http://www.pymol.org

12. Berger, O.; Edholm, O.; Jahnig, F. Biophys J 1997, 72, 2002. 